\title{
EXTERNAL FIXATION FOR TYPE III OPEN TIBIAL FRACTURES
}

\author{
C. M. COURT-BROWN, E. F. WHEELWRIGHT, J. CHRISTIE, M. M. MCQUEEN
}

\author{
From Royal Infirmary of Edinburgh and Princess Margaret Rose Orthopaedic Hospital
}

\begin{abstract}
An analysis of 51 type III open tibial fractures treated by external skeletal fixation is presented. The fractures are subdivided according to the classification of Gustilo, Mendoza and Williams (1984) into types IIIa, IIIb and IIIc. The different prognoses of these fracture subtypes is examined.

The use of the Hoffmann and Hughes external fixators in the management of type III open tibial fractures is presented and it is suggested that the prognosis is independent of the type of fixator used.
\end{abstract}

External skeletal fixation has become accepted by most surgeons as the treatment of choice for type III open tibial fractures (Gustilo and Anderson 1976). Good results have been reported by a number of authors although few have divided their fractures according to Gustilo's later classification (Gustilo et al 1984) which subdivides the type III fractures into three types according to the degree of periosteal damage, the amount of contamination and the presence of major vessel injury. Gustilo et al (1984) and Caudle and Stern (1987) discussed the treatment of these different subtypes. However, their treatment methods were heterogeneous. We report the results of external skeletal fixation in the management of type III open tibial fractures.

\section{MATERIALS AND METHODS}

Between January 1982 and December 1986, 61 type III open tibial fractures were treated with external skeletal fixation in the orthopaedic trauma unit of the Royal Infirmary of Edinburgh. Four patients died from the effects of multiple injuries and a further six were

C. M. Court-Brown, MD, FRCS Ed(Orth), Senior Lecturer and Consultant Surgeon

M. M. McQueen, FRCS Ed(Orth), Senior Lecturer and Consultant Surgeon

University of Edinburgh, Department of Orthopaedic Surgery, Princess Margaret Rose Orthopaedic Hospital, Fairmilehead, Edinburgh EH10 7ED, Scotland.

E. F. Wheelwright, FRCS, Senior Registrar in Orthopaedics J. Christie, FRCS Ed, Consultant Orthopaedic Surgeon

Royal Infirmary of Edinburgh, 1 Lauriston Place, Edinburgh EH3 9DW, Scotland.

Correspondence should be sent to Mr C. M. Court-Brown.

(C) 1990 British Editorial Society of Bone and Joint Surgery $0301-620 X / 90 / 5160 \$ 2.00$

J Bone Joint Surg [ Br] 1990; 72-B :801-4. transferred to other centres or lost to follow-up. Thus, 51 fractures were examined retrospectively to analyse the differences between the three subtypes of type III fracture and to examine the role of external skeletal fixation in their management.

There were 15 females and 36 males with a mean age of 37.7 years (range 14 to 81 ). Of these, $46(90 \%)$ were patients who had been injured in road traffic accidents; 13 had been passengers in cars; 15 were either motor cycle riders or passengers; and 18 were pedestrians. Isolated tibial fractures or minor associated injuries occurred in 27 patients, but the other 24 had multiple injuries.

All the fractures were treated by early and thorough wound toilet and the application of an external fixation frame. The choice of external fixator was made by the surgeon but both the unilateral Hughes fixator and the Hoffmann device were available. The configuration of application of the fixator was selected by the surgeon, this depending mainly on the type of fracture and the extent and location of the soft-tissue injury.

All surgery was performed using prophylactic cefuroxime and penicillin. Antibiotic administration was continued in many patients either because of the severity of the fracture or the nature of other injuries. Plastic surgeons were involved early in the treatment regime and they undertook all flap cover, although if split-skin grafting was required this was performed by orthopaedic surgeons. Every attempt was made to provide skin cover within the first week.

Postoperative mobilisation was largely dictated by the nature and extent of any associated injuries. Patients with isolated tibial fractures were mobilised as soon as there was adequate soft-tissue healing, but they remained non-weight-bearing until the fixator was removed or until 
bone union was in evidence. A policy of early bone grafting was followed, this usually being performed within the first 12 weeks if the surgeons considered that union would be delayed.

The duration of external fixation was determined by the surgeon and was based on the state of the soft tissues, the extent of bone union and the patient's desire to have the fixator removed. A previous review of type II tibial fractures treated by external fixation (Court-Brown and Hughes 1985) had shown poor results if the fixators were removed at an early stage. Consequently, the surgeons tended to keep the fixators on until well after the soft tissues had healed; however, all patients had the fixators removed before bone union and were placed in a patellabearing cast until union had occurred. The follow-up was for a minimum of two years.

Malreduction and malunion were defined as being present when there was more than $5^{\circ}$ of rotational or angular deformity or more than $1 \mathrm{~cm}$ of shortening. Pin track sepsis was defined as local erythema or discharge.

\section{RESULTS}

Type IIIa fractures. There were 20 type IIIa fractures with a mean time to union of 26.5 weeks. Of these, half were bone grafted and two $(10 \%)$ required flap cover of the skin defect; the remainder were treated by secondary suture or split-skin grafting. Fourteen patients were treated with a Hughes fixator and six with a Hoffmann device (four with triangular configurations and two with Hoffmann-Vidal double frame configurations).

The mean period of external fixation was 9.7 weeks (range 3 to 17); the mean duration of the Hughes fixator was 9.1 weeks and that of the Hoffmann 11.0 weeks. With the Hughes fixator the mean time to union was 24.2 weeks, with the Hoffman it was 33.6 weeks. There was one case $(5 \%)$ of Pseudomonas aeruginosa osteomyelitis and five cases $(25 \%)$ of either erythema around a transfixion pin or discharge from a pin track.

There were 17 fixators applied with the fracture acceptably reduced, but four of these united with significant recurvatum (three had been treated with a Hughes fixator and one with a Hoffmann-Vidal double frame). The three fractures that were malreduced initially all healed in a malreduced position. The mean hospitalisation time of this IIIa group was 71.6 days (43.6 days for those with isolated fractures and 114.2 days for the multiply injured group). Return to work was at an average of 31.5 weeks after the fracture.

At two years after injury, 11 patients $(55 \%)$ had returned to full activities, five $(25 \%)$ felt that their activity level had been reduced but did not require walking aids, three $(15 \%)$ required walking aids and one $(5 \%)$ was grossly disabled following a head injury sustained at the time of the accident. Eight patients $(40 \%)$ had joint stiffness at two years, two at the knee and six at the ankle or subtalar joint.
Type IIIb fractures. There were 17 type IIIb fractures with a mean time to union of 47.4 weeks. Of these, three $(17.6 \%)$ patients required amputation; one had a primary amputation because of the extent of coexisting injuries and two had later amputations at four and 18 months because of severe neurological damage and extensive osteomyelitis respectively. Of the remaining 14 fractures, $11(78.6 \%)$ required bone grafting and eight $(57.1 \%)$ required flap cover. Eleven patients were treated with a Hughes fixator with a mean union time of 49.6 weeks and three with a Hoffmann-Vidal double frame, these having a mean union time of 37.3 weeks.

The mean duration of external fixation for the IIIb group was 12.6 weeks (range 5 to 26). The Hughes fixators were retained for an average of 13.7 weeks and the Hoffmann device for an average of 8.6 weeks. There were five $(35.7 \%)$ cases of osteomyelitis and seven $(50 \%)$ patients showed signs of pin discharge or local erythema. Of the five cases of osteomyelitis two were caused by Staphylococcus aureus, two by Pseudomonas aeruginosa, and one by Escherichia coli.

Of the fractures that united, nine had an acceptable initial reduction; however, only four of these healed in an acceptable position, giving an overall malunion rate of $71.4 \%$. As with the type IIIa fractures the commonest deformity after an initially adequate reduction was recurvatum, although valgus and shortening were also seen. The mean hospitalisation time was 75.1 days with a mean of 76.5 days for the isolated fractures and 74.1 days for the multiply injured group. Return to work was after an average of 63.7 weeks.

At two years after injury, four of the non-amputation group $(28.6 \%)$ had returned to full activity. Five patients $(35.7 \%)$ had returned to reduced activities but did not require walking aids and the remaining five $(35.7 \%)$ required a walking aid; $70 \%$ of patients had some residual joint stiffness two years after injury.

Type IIIc fractures. There were 14 type IIIc fractures, of which $12(85.7 \%)$ required amputation. Half of these had a primary amputation; in the remaining six the amputation was undertaken between five days and six weeks after the initial injury (four because of sepsis, one because of vascular insufficiency and one because of the extent of coexisting injuries). The average age of the six patients undergoing primary amputation was 51.8 years.

Of the two patients who went on to union after initial vascular repair and external fixation, one healed at 59 weeks and the other at 70 weeks. They required seven and nine operations respectively, and one had osteomyelitis caused by Pseudomonas aeruginosa. However, both returned to full activities despite significant malunion.

Overall results. The overall mean time to union of the whole series was 36.7 weeks: $70 \%$ of the patients were bone grafted and there was a $17.6 \%$ incidence of osteomyelitis, of which $71.4 \%$ were caused by gramnegative organisms; and $35 \%$ of the patients had signs of 
pin track infection. The fractures treated with the Hughes fixator united in a mean of 36.7 weeks; in those treated with the Hoffmann device the mean was 37.9 weeks.

\section{DISCUSSION}

Our overall results compare well with those of other series describing the use of external fixation in type III open tibial fractures (Karlström and Olerud 1975; Lawyer and Lubbers 1980; Chan et al 1984; Caudle and Stern 1987). Union is reported to occur between 34.2 weeks (Karlström and Olerud 1975) and 38.1 weeks (Lawyer and Lubbers 1980). The incidence of infection varies between $0 \%$ (Karlström and Olerud 1977) and 38\% (Chan et al 1984) although Caudle and Stern (1987) in their detailed analysis of type III tibial fractures, had a $24.1 \%$ infection rate in their non-amputation group. In addition, Chan et al (1984) document a $41 \%$ incidence of malunion and a $62.5 \%$ incidence of joint stiffness.

The results for the different fracture subtypes highlight the importance of classifying these fractures adequately and suggest that the criteria on which Gustilo et al (1984) based their subclassification of type III fractures are appropriate. It is clear that each of the type III subtypes carries a very different prognosis. Type IIIa fractures are associated with a low incidence of infection and a relatively good functional result, with return to work at an average of only four weeks after union.

Type IIIb fractures carry a significantly worse prognosis, not only in the time to union but in the number of amputations and the marked increase in the incidence of osteomyelitis. This was also recorded by Caudle and Stern (1987) who had no infections in their IIIa group, but a $29 \%$ infection rate in their IIIb group. In addition, the hospitalisation time for isolated IIIb fractures in our series averaged 31.5 days more than that of the IIIa fractures, and the fact that this time was similar to that for the multiply injured patients with IIIb fractures suggests that it was the IIIb fracture which was the determining factor in hospital discharge. Return to work was delayed and many fewer patients achieved full joint function or full mobility.

The incidence of amputation in the type IIIc fractures was very high and reflects the severity of injury. The six primary amputations did not have vascular repairs, and it might be argued that their prognosis might have been different had repairs been performed. However, in each case the decision to amputate was based on the severity of the muscle injury, and in four of the cases also on the age of the patient (over 65 years). Caudle and Stern (1987) report a $78 \%$ overall amputation rate in type IIIc tibial fractures and Hansen (1987) has highlighted the considerable morbidity associated with attempted salvage of these severe injuries. Despite the fact that our two successfully treated IIIc patients eventually had good function, it is clear that the prognosis for the type IIIc fractures is poor, and we would support the protocol suggested by Lange et al (1985) advocating the conditions in which primary amputation should be performed.

External skeletal fixation is advocated by most authorities as the method of choice for type III tibial fractures (Karlström and Olerud 1983; Chapman 1986; Burgess et al 1987), although few workers have drawn attention to the associated complications. Chan et al (1984) also advocated external fixation although they did draw attention to some of the associated problems. Our results show that there are problems, particularly pin track sepsis and malunion; $25 \%$ of the IIIa and $50 \%$ of the IIIb fractures showed signs of pin track sepsis. These figures compare with those of other workers (Behrens and Searls 1986). In our study $3 \mathrm{~mm}$ pins were used with the Hoffmann fixator, and $4.8 \mathrm{~mm}$ pins in the Hughes system; despite the difference in size there was no difference in pin sepsis between the two devices.

Eight of the type IIIa and IIIb fractures were not reduced adequately at the time of initial external fixation and all these fractures healed in a malunited position. Of the 29 fractures that were initially reduced, nine eventually healed in a malreduced position, the loss of reduction occurring after the fixator was removed. This highlights the dilemma of when to remove a fixator from type III fractures. The duration of external fixation in our study was similar to that in other series (Karlström and Olerud 1977; Velazco and Fleming 1983), but the prolonged union times associated with type III fractures means that surgeons can expect a significant incidence of malunion unless the fixator is retained for much longer periods than we used.

Extensive biomechanical investigation has been undertaken into the optimal design of tibial external fixators (Burny 1979; Egkher, Martinek and Wielke 1980; McCoy, Chao and Kasman 1983). However, the similar overall results of both the Hughes and Hoffmann devices suggest that neither is superior, and we agree with Behrens and Searls (1986) that the results of external fixation are independent of the type of frame employed. We believe that good results depend on good surgical technique, early full thickness flap cover and an understanding of the basic principles of external fixation, rather than on the use of a specific fixator. Currently we use both unilateral and multiplanar fixators, but the decision is based on the fracture configuration and the location and extent of soft-tissue defects.

No benefits in any form have been received or will be received from a commercial party related directly or indirectly to the subject of this article.

\section{REFERENCES}

Behrens F, Searls K. External fixation of the tibia: basic concepts and prospective evaluation. J Bone Joint Surg [Br] 1986; 68-B: 246-54.

Burgess AR, Poka A, Brumback RJ, et al. Management of open grade III tibial fractures. Orthop Clin North Am 1987; 18:85-93. 
Burny FL. Elastic external fixation of tibial fractures: study of 1421 cases. In: Brooker AF Jr, Edwards C, eds. External fixation - the current state of the art. Procs of 6th International Conference on Hoffman External Fixation. Baltimore: Williams and Wilkins, 1979:55-73.

Caudle RJ, Stern PJ. Severe open fractures of the tibia. $J$ Bone Joint Surg [ Am] 1987; 69-A :801-7.

Chan KM, Leung YK, Cheng JCY, et al. The management of type III open tibial fractures. Injury 1984; 16:157-65.

Chapman MW. The role of intramedullary fixation in open fractures. Clin Orthop 1986; 212:26-34.

Court-Brown CM, Hughes SPF. Hughes external fixator in treatment of tibial fractures. $J R$ Soc Med 1985; 78:830-7.

Egkher E, Martinek $\mathbf{H}$, Wielke B. How to increase the stability of external fixation units. Arch Orthop Traumat Surg 1980; 96:35-43.

Gustilo RB, Anderson JT. Prevention of infection in the treatment of one thousand and twenty-five open fractures of long bones. $J$ Bone Joint Surg [ Am] 1976; 58-A :453-8.

Gustilo RB, Mendoza RM, Williams DN. Problems in the management of type III (severe) open fractures: a new classification of type III open fractures. J Trauma $1984 ; 24: 742-6$
Hansen ST Jr. Editorial. The type-IIIC tibial fracture: salvage or amputation. J Bone Joint Surg [Am] 1987; 69-A :799-800.

Karlström G, Olerud S. Percutaneous pin fixation of open tibial fractures: double-frame anchorage using the Vidal-Adrey method. J Bone Joint Surg [Am] 1975; 57:915-24.

Karlström G, Olerud S. Stable external fixation of open tibial fractures. Orthop Rev 1977; 6:25.

Karlström G, Olerud S. External fixation of severe open tibial fractures with the Hoffmann frame. Clin Orthop 1983; 180:68-77.

Lange RH, Bach AW, Hansen ST Jr, Johansen KH. Open tibial fractures with associated vascular injuries: prognosis for limb salvage. $J$ Trauma $1985 ; 25: 203-8$.

Lawyer RB, Lubbers LM. Use of the Hoffmann apparatus in the treatment of unstable tibial fractures. J Bone Joint Surg [Am] $1980 ; 62-A: 1264-73$.

McCoy MT, Chao EYS, Kasman RA. Comparison of mechanical performance in four types of external fixators. Clin Orthop 1983; $180: 23-33$.

Velazco A, Fleming LL. Open fractures of the tibia treated by the Hoffmann external fixator. Clin Orthop 1983; 180:125-32. 